NBER WORKING PAPER SERIES

\title{
CURRENCY OPTION PRICING IN \\ CREDIBLE TARGET ZONES
}

Bemard Dumas

L. Peter Jennergren

Bertil Nasslund

Working Paper No. 4522

\section{NATIONAL BUREAU OF ECONOMIC RESEARCH \\ 1050 Massachusetts Avenue \\ Cambridge, MA 02138 \\ November, 1993}

This paper is part of NBER's research programs in Asset Pricing and International Finance and Macroeconomics. Any opinions expressed are those of the authors and not those of the National Bureau of Economic Research. 


\title{
CURRENCY OPTION PRICING IN CREDIBLE TARGET ZONES
}

\begin{abstract}
This paper develops a model for valuing options on a currency which is maintained within a band. The starting point of our model is the well known Krugman model for exchange-rate behavior within a target zone. Results from model tuns provide insight into evidence reported by other authors of mispricing of currency options by extensions of the Black-Scholes model.
\end{abstract}

Bernard Dumas

HEC School of Management

78351 Jouy-en-Josas

FRANCE

and NBER

Bertil Näslund

Stockholm School of Economics

S-11383 Stockholm

SWEDEN
L. Peter Jennergren

Stockholm School of Economics.

S-1I383 Stockholm

SWEDEN 


\section{Introduction}

The Black-scholes framework is often used for valuing currency options. A simple variant of that framework, which is actualiy only a slight extension of the Black-scholes formula, is the well-known Garman-Kohlhagen model (Garman and Kohlhagen [1983]). However, this class of models is only valid for situations with freely floating currencies. Many currencies are not freely floating but constrained to move within explicit target zones. Most importantly, this holds for the currencies within the European Monetary system (EMS). The bilateral exchange rates of those currencies are maintained within bands by central bank interventions. Those bands are \pm 2.25 z around central parity, except for spain and the UK $( \pm 6$ s). For another example, the exchange rate of the swedish currency (Crown) against ECU is sioilarly maintained within a band of 1.5 around central parity. These target zones are explicit, but in addition there may be implicit target zones for ostensibly freely floating currencies, established urider the Louvre agreement. currency dealers take account of implicit target zones, according to one informed source in the banking industry. Due to the importance of target zones, and the difference between target zones and freely 
floating currencies, it is of considerable interest to study the pricing of options in such exchange rate regimes.

In this paper, we show how to price options on currencies in target zones. For that reason, we need a model for exchange rate behavior within such a zone, as a starting point. We take the most influential of such models as our point of departure, the one developed by krugran [1991]. Although published only in 1995, Krugman's paper has been circulated since 1988 and has become the beginning of an entire literature on exchange rate target zones (e. g., Krug̣man and M11ler [1992]).

The Krugman model makes two main assumptions: In the first place, the target zone is credible $(i, e .$, there are no realignments). In the second place, interventions to defend the target zone take place at the edges of the band. A main result in the Krugman model is that the logarithm of the exchange rate is an S-shaped function of a market fundamental (money supply and "velocity"). Also, the exchange rate is insensitive to the fundamental at the edges of the band, because of "swooth pasting".

Very specific predictions follow from the Krugman model. Those predictions have been tested empirically, and have as a rule been rejected (see, for instance, Lindberg and soderlind [1992]\}. For instance, the krugman model predicts that the distribution of the logarithm of the exchange rate should be U-shaped and hence concentrated towards the end points of the band. Empirical investigations reveal a hump-shaped 
distribution, though, with most of the probability mass in the interior of the band. Empirical investigations also reveal that target zones are not totally credible.

Due to the importance of the Krugman model, we take it as our point of departure, as already mentioned, despite the fact that some of its predictions have been falsified empirically. However, in the conclusion (Section IV), we indicate briefly an alternative approach to currency option pricing in a target zone which is not founded on the krugman model.

The outline of this paper is as follows: section II presents our currency option valuation model. Section III gives results from sample model runs. Those results provide some insight into mispricing of currency options by extensions of the Black-Scholes model which has been reported by other authors. Section IV contains concluding remarks.

II. A Model for Currency option Valuation in a Credible Target Zone

As is well known, in the krugroan target zone model the log of the domestic price of foreign exchange, denoted $e$, is equal at time $t$ to a fundamental, $f(t)$, plus a term proportional to the interest rate differential between the two currencies. The latter is equal to the expected change in the logarithm of the exchange rate: 


$$
\begin{aligned}
& e(f)=f(t)+\alpha\left(r_{D}-r_{F}\right) \quad(\alpha>0), \\
& r_{D}-r_{F}=E[d e] / d t, \\
& e(f)=f(t)+\alpha E[d e] / d t,
\end{aligned}
$$

where $E$ denotes expectation and $r_{D}$ and $r_{F}$ are the domestic-currency and foreign-currency riskfree rates of interest. The fundamental is constrained through foreign-exchange market interventions to lie within a band with lower and upper boundaries $\underline{f}$ and $\bar{f}$. Inside that band, the fundamental follows Brownian motion with a drift:

$d f=\mu d t+\sigma d z$.

The solution to (1) is

$$
\begin{aligned}
e(f) & =f+\alpha\left\{0.5 \sigma^{2} e_{E f}+\mu e_{f}\right\} \\
& =f+\alpha \mu+A_{1} \exp \left(\rho_{1} f\right)+A_{2} \exp \left(\rho_{2} f\right) .
\end{aligned}
$$

where $p_{1}$ and $\rho_{2}$ are the roots of the characterfstic equation

$$
0.5 \alpha \sigma^{2} \rho^{2}+\alpha \mu \rho-1=0 .
$$

The function $e(f)$ given by (2) is defined for $f \leq f \leq \bar{f}$. $A_{1}$ and $A_{2}$ are determined by means of the smooth pasting conditions

$$
e_{E}(\underline{f})=e_{f}(\bar{f})=0 \text {, }
$$


i. e.,

$$
\begin{aligned}
& 0=1+A_{1} \rho_{1} \exp \left(\rho_{1} f\right)+A_{2} \rho_{2} \exp \left(\rho_{2} f\right), \\
& 0=1+A_{1} \rho_{1} \exp \left(\rho_{1} \bar{f}\right)+A_{2} \rho_{2} \exp \left(\rho_{2} \bar{f}\right),
\end{aligned}
$$

and are equal to

$$
\begin{aligned}
A_{1}= & \left\{\exp \left(\rho_{2}(\underline{f}-\bar{f})\right)-1\right\} / \\
& \left\{\rho_{1} \exp \left(\rho_{1} \underline{f}\right)-\rho_{1} \exp \left(\rho_{1} \bar{f}\right) \exp \left(\rho_{2}(\underline{f}-\bar{f})\right)\right\}, \\
A_{2}= & \left\{\exp \left(\rho_{1}(\underline{f}-\bar{f})\right)-1\right\} / \\
& \left\{\rho_{2} \exp \left(\rho_{2} \underline{f}\right)-\rho_{2} \exp \left(\rho_{2} \bar{f}\right\} \exp \left(\rho_{1}(\underline{f}-\bar{f})\right)\right\} .
\end{aligned}
$$

If there is no band on the fundamental, the free-float solution $e=f+\alpha \mu$ is obtained (cf. Flood and Garber [1991], Froot and Obstfeld [1991], Krugman [1991], Svensson [1991]).

In our currency option valuation model, the band which is initially given is that on the log exchange rate, not on the fundasental. That is, the central bank(s) may be thought of as announcing that it (they) will keep the log exchange rate between $\mathrm{e}$ and $\overline{\mathrm{e}}$ (rather than the fundamental between $\underline{E}$ and $\bar{f}$ ). In the Krugman model, the interventions which occur at the edges of the log exchange rate band are infinitesimal, and this leads to a uniquely determined band on the fundamental (Delgado and Dumas [1990], Froot and obstfeld [1991, 213], Svensson [1991, 36-37]). Hence, we need not worry about multiple bands on the fundamental for a given log exchange rate band. In our numerical work, we 
start with $\underline{e}$ and $\bar{e}$ and obtain $\underline{f}$ and $\overline{\bar{f}}$ such that $e(\underline{f})=\underline{e}$ and $e(\bar{f})=\bar{e}$ through a search procedure.

It is seen that the interest rate differential $r_{D}-r_{F}=$ $0.5 \sigma^{2} e_{f f}+\mu e_{f}$ is specified in the krugman model, but not the absolute level of $r_{D}$ or $r_{F}$. Since the absolute level of $r_{D}$ is needed for the currency option valuation model, we make the following assumption about how $I_{D}$ and $r_{F}$ move in order to accomodate changes in the interest rate differential:

$$
\begin{aligned}
& r_{D}=r+0.5\left(0.5 \sigma^{2} e_{f f}+\mu e_{f}\right) \\
& r_{F}=r-0.5\left(0.5 \sigma^{2} e_{f f}+\mu e_{f}\right) .
\end{aligned}
$$

In other words, $r_{D}$ and $r_{F}$ are specified as deviations from a central interest rate $r$.

After these preparations, we can specify our currency option valuation model, which is applicable to call options of the Furopean type. Ito's lemma implies

$$
d e=\left(0.5 \sigma^{2} e_{f f}+\mu e_{f}\right) d t+e_{f} \sigma d z .
$$

Let $s$ be the absolute value of the exchange rate, i. e., $s=$ exp(e). Again by Ito's lemma,

$$
d s=\left(0.5 \sigma^{2} e_{f f}+\mu e_{f}+0.5\left(e_{f} \sigma\right)^{2}\right) s d t+e_{f} \sigma s d z .
$$

Let $V(S, T)$ denote the value of the currency option, as a function 
of the exchange rate $S$ and time $T$ to expiration. By the usual arbitrage argument, we derive the following valuation equation for $v(S, \tau)$ :

$$
\begin{aligned}
& 0.5\left(e_{f} \sigma\right)^{2} s^{2} v_{s s}+\left(0.5 \sigma^{2} e_{f f}+\mu e_{f}\right) s v_{S}-v_{T}- \\
& \left(r+0.5\left(0.5 \sigma^{2} e_{f f}+\mu e_{f}\right)\right) v=0 .
\end{aligned}
$$

It is understood in (4) that $e_{f}$ and $e_{f f}$ are evaluated at $f$ such that $\exp (e(f))=S$. Equation (4) is the same as would be obtained, if one were to write down the corresponding valuation equation for an investor in the foreign country and then change variables to express the option value as a function of the $10 \mathrm{~g}$ of the domestic price of foreign exchange and in terms of domestic money units.

We now substitute variables twice; first to obtain the log of the exchange rate as underlying state variable, and after that to obtain the fundamental $f$ as underlying state variable. We arrive at the following equation, where $U(f, T)$ is the value of the currency option, as a function of the fundamental $f$ and time to expiration $\mathrm{t}$ :

$$
\begin{aligned}
& 0.5 \sigma^{2} U_{f f}+\left(\mu-0.5 e_{f} \sigma^{2}\right) U_{f}-U_{\tau}- \\
& \left(r+0.5\left(0.5 \sigma^{2} e_{f f}+\mu e_{f}\right)\right) v=0 .
\end{aligned}
$$

The initial condition (at $t=0$, $i$. e., at maturity) is 


$$
U(f, 0)=\max [0, \exp (e(f))-\exp (R)],
$$

where $R$ is the $\log$ of the exercise price (exercise exchange rate). Smooth pasting applies to the currency option, as well as to the log exchange rate, so the boundary conditions are

$$
U_{f}(\underline{f})=0, \text { and } U_{f}(\bar{f})=0 \text {. }
$$

It is the convenience in writing these boundary conditions which leads us to use the fundamental rather than log exchange rate for exchange rate) as underlying state variable.

The valuation equation (5), the initial condition (6), and the boundary conditions (7) together constitute the currency call option valuation model. It is essentially the same as the GarmanKohlhagen model (Garman and Kohlhagen (1983]), when the band on the fundamental becomes very wide.

III. Some Results Regarding Currency Option Valuation

In this section, we discuss sample results from the currency option valuation model of the previous section. Our purpose is to exhibit qualitative aspects of currency option pricing in a target zone. In particular, we will show how a target zone (explicit or implicit) may explain mispricing by other currency option pricing models which has been documented by previous authors. 
A11 model runs in this section pertain to a band on the log exchange rate with lower bound $e$ of -0.03268 and upper bound $\bar{e}$ of 0,04868 . This means that the corresponding lower and upper bounds. on the exchange rate exp(e) and exp(e) are 0.96785 and 1.04988 . Results (computed option value functions over the entire exchange rate band) are displayed as graphs, in Figures 1 and 2 , with absolute option values plotted against absolute exchange rates.

The exercise price exp(R) (exercise exchange rate) has been set to $\exp \left(\left(e^{+}+\bar{e}\right) / 2\right)=1,008$. The time to expiration is 6 months in Figure 1 and 12 months in Figure 2. The central interest rate $r$ is equal to 0.1 . The remaining parameters are as follows: $\alpha=0.5, \mu=0.0$, and $\sigma=0.1$.

At this point, a few words about parameter values are called for. Other authors have tried to estimate the parameters in the krugman target zone model, but the results are probably not very reliable. Estimates of $\alpha$ vary, but generally they fall between 0.1 and 1 (see Flood, Rose, and Mathieson [1991]; and Lindberg and söderlind [1991]). A very low value for $\sigma ; 0.0086$, was estimated by Lindberg and söderlind [1991, 15]. As for $\mu$, there does not seem to be much information available.

Consider now Figures 1 and 2 . As already indicated, the only difference between these two figures refers to the time to expiration, which is 6 months in Figure 1 but 12 months in Figure 2. The upper-most curves narked "a" and "d" are value functions for a very wide band. They are hence essentially the same as the Garman-Kohlhagen solutions, where the log exchange rate equation 
is the free float equation $e(f)=f$ (it is noted that $\mu=0$ ). The Garman-Kohlhagen value functions extend to the right. and left in the figures, of course; only those portions which fall inside the exchange rate band under consideration are shown in the figures. The figures also show the option value functions when the band is set as indicated above (the curves marked " $c$ " and "f"). It is seer that the imposition of a target zone leads to substantially lower computed option values.

However, the comparison between the two curves "a" and "c", or the two curves " $\mathrm{d}$ " and "f", is unfair, in that the variability of the log exchange rate is much lower in an option pricing wodel incorporating a target zone than in the Garman-Kohlhagen model. The variability in the latter model is $\sigma$. From equation (3) in Section 2 , 1t is seen that the varlability of the 109 exchange rate in the former model is $e_{f} \sigma$. In order to provide a fairer comparison between the two models, we rerun the Garman-Kohlhagen model with $\sigma$ set to $E\left[\sigma_{e}\right]$, the average variability of the log exchange rate in the currency option valuation model with a target zone.

More precisely, for $\mu$ equal to zero, the fundamental $f$ has the asymptotic density $\varphi(f)=1 /(\bar{f}-\underline{f})$ (for $\underline{f} \leq \leq \bar{f}$ ). For $\mu$ different from zero, the asymptotic density is $\varphi(f)=$ $\theta \exp (\theta \mathrm{f}) /[\exp (\theta \overline{\mathrm{f}})-\exp (\theta \underline{\underline{f}})]$, where $\theta=2 \mu / \sigma^{2}$ (Svensson (1991, 37]). Taking the expectation of $\sigma_{e}, E\left[\sigma_{e}\right]=\varepsilon\left[\epsilon_{f}^{\sigma}\right]$, which in turn equals 


$$
\int_{\underline{f}}^{\bar{f}} e^{\sigma \varphi(f) d f .}
$$

We obtain

$$
\begin{aligned}
& E\left[\sigma_{e}\right]= \\
& \sigma\left[1-\left\{2 /\left(\rho_{1}(\bar{f}-\underline{f})\right)\right\}\left\{\left(\cosh \left(\rho_{1}(\bar{f}-\underline{f})\right)-1\right) / \sinh \left(\rho_{1}(\bar{f}-\underline{f})\right)\right\}\right],
\end{aligned}
$$

when $\mu=0$ (it is noted that $\rho_{2}=-\rho_{1}$ in that case). For $\mu \neq 0$, $E\left[\sigma_{e}\right]$ equals

$$
\sigma\left[1+\frac{\left(\theta / \rho_{1}\right) \cosh \left(\rho_{1}(\overline{\mathrm{f}}-\underline{\mathrm{f}})\right)-\left(\theta / \rho_{1}\right)-\left(\theta / \rho_{2}\right) \cosh \left(\rho_{2}(\overline{\mathrm{f}}-\underline{\underline{f}})\right)+\left(\theta / \rho_{2}\right)}{\cosh \left(\rho_{1}(\overline{\mathrm{f}}-\underline{f})\right)-\cosh \left(\rho_{2}(\overline{\mathrm{f}}-\underline{f})\right)}\right] .
$$

In both cases, $E\left[\sigma_{e}\right]$ goes to zero, as the width of the band on the fundamental goes to zero. Also, the second expression for $E\left[\sigma_{e}\right]$ converges to the first one, as $\theta$ goes to zero (these limits can be shown using 1 'Hospital's rule). E[ $\left.\sigma_{e}\right]$ apparently approaches $\sigma$, as the band on the fundamental becomes very wide, if $\mu=0$. However, that limit does not hold in the second case $(\mu \neq 0)$.

In our case, $\mathbf{E}\left[\sigma_{e}\right]=0.04634$. Rerunning the Garman-Kohlhagen model with $\sigma$ equal to 0.04634 rather than equal to 0.1 gives the curves "b" in Figure $I$ and "e" in Figure 2. 
It is interesting to note that the Garman-Kohlhagen model now gives Iower computed option values than our currency option valuation model, for out-of-the-money options. The same is also true for at-the-money options with 6 months to expiration (see Figure 1). The relative difference between the two models for out-of-the-money options is actually quite large.

This may throw some light on evidence of underpricing of out-of-the-money currency call optiong by the Garman-Kohlhagen model which has been reported by some authors (Borensitein and Dooley [1987]; Bodurtha and Courtadon [1987]; cf, also Courtadon [1990)]. It has been suggested that this type of mispricing could be eliminated by using a jump-diffusion model along the lines of Merton [1976], rather than the Garman-Kohlhagen model (Bodurtha and Courtadon [1987, 164-165]; Jorion [1988]).

However, we would like to suggest another possible explanation for this bias: The currency in question could be subject to an implicit target zone. The evidence reported by Borensztein and Dooley [1987] and Bodurtha and Courtadon [1987] pertains to options to buy foreign currencies (British pounds, Canadian dollars, German marks, Japanese yen, and French and Swiss francs) for us dollars. The us dollar is not subject to an explicit exchange rate band, of course, but there could be an implicit reference zone, as also suggested by krugman [1991, 669]. The time period in the Borensztein-Dooley and Bodurtha-courtadon investigations was early 1983 to early 1985. During that time period, the us dollar was considered very strong 
(Borensztein and Dooley $[1987,645])$. That is, the us dollar could have been near the lower end of some lmplicit target zone. If so, that could perhaps explain the fact that the GarmanKohlhagen model was found to have underpriced currency call options during that time period.

It is also interesting to note that the option value functions "c" and "f" are more or less straight lines, and that the slope of the forwer is greater than that of the latter. In fact, if the time to expiration becomes very long, the option value function with a target zone will eventually become a horizontal straight line across the diagram. In other words, the option value is asymptotically independent of the current exchange rate. This result, which holds also vhen $\mu \neq 0$, follows since the fundamental has an asymptotic distribution which does not depend on its starting value), as mentfoned above. It is also seen that the value of a currency option need not increase with increasing time to expiration (compare the right-most parts of curves "c" and "f").

IV. Conclusion

On the basis of the Krugman target zone model, this paper has presented a model for currency option valuation. As indicated in the introduction, the Krugman model has been criticised for generating predictions which do not agree with the empirical evidence. For that reason, one could have considered taking 
another target zone model as a starting point, and we will briefly indicate one possibility.

Rather than assuming that interventions take place only at the edges of the band, one may assume interventions inside the band increasing in size, as the exchange rate moves away from some preferred level. This can be formalized by assuming that the fundamental follows an ornstein-Uhlenbeck process inside the band (see Delgado and Dumas [1992]; Lindberg and Söderlind [1992]). If so, the log of the exchange rate inside the band obeys a second-order differential equation with an associated homogeneous equation known as Kummer's equation. The resulting solution for the log exchange rate is known (see Lindberg and söderlind $(1992,17])$. One could then build a currency option valuation model on that foundation. This would be an interesting direction for further research.

Another criticism of the Krugman model is that target zones are not necessarily credible (as was clearly demonstrated during the writing of this paper, in september 1992, when several European countries devalued their curfencies). Another Interesting research direction would therefore be to extend the Krugran model to incorporate a realignment mechanisw and then to construct an option valuation model for such a situation. Elsewhere, we have taken a preliminary step in that direction (Dumas, Jennergren, and Näslund [1992]; cf. also Bertola and Sversson (1990), BaIl and Roma [1990]).

In conclusion, in this paper we have derived and implemented 
a currency option valuation model which incorporates the target zone feature. We have used results from our model to reconsider the underpricing of out-of-the-money currency options by the Garman-Kohlhagen model which has been documented by earlier authors. It appears that such underpricing could be explained by an implicit band on the currency in question.

\section{References}

Ball, Clifford. A., and Antonio Roma, 1990, The European monetary system, jump-diffusion processes, and the pricing of options. working paper.

Bertola, Giuseppe, and Lars E. O. Svensson, 1990, stochastic devaluation risk and the empirical fit of target zone models. Seminar paper no. 481, Institute for. International Economic studies, University of stockholm.

Bodurtha, James N., Jr., and Georges R. Courtadon, 1987, "Tests of an American Option Pricing Model on the Foreign currency Options Market," Journal of Financial and Quantitative Analysis 22, 153-167.

Borensztein, Eduardo R., and Michael P. Dooley, 1987, "options on Foreign Exchange and Exchange Rate Expectations," IMF Staff Papers 34, 643-680.

Courtadon, Georges R., 1990, "Recent Trends in Foreign Currency option Valuation," in Options, ed. Stewart Hodges, Manchester: Manchester University Press, 141-160.

Delgado, Francisco, and Bernard Dumas, 1990, Honetary contracting between central banks and the design of sustainable exchange-rate zones. Horking paper no. 3440, NBER (forthconing in Journal of International Economics).

Delgado, Francisco, and Bernard Dumas, 1992, "Target zones, Broad and Narrow," In Exchange Rate Targets and Currency Bands, eds. Paul Krugman and Marcus Miller, Cambridge: Cambridge university Press, 35-56.

Dumas, Bernard, L. Peter Jennergren, and Bertil Näslund, 1992, Realignment risk and currency option pricing in target zones. Research paper no. 6478, The Economic Research Institute, Stockholm School of Economics.

Flood, Robert P., and Peter M. Garber, 1991, "The Linkage between Speculative Attack and Target Zone Models of Exchange Rates," Quarterly Journal of Economics 106, $1367-1372$. 
Flood, Robert P., Andrew K. Rose, and Donald J. Mathleson, 1991, "An Empirical Exploration of Exchange-Rate Target Zones," Carnegie-Rochester Series on Public Policy 35, 7-66.

Froot, Kenneth A., and Maurice obstfeld, 1991, "Exchange-Rate Dynamics under stochastic Regime Shifts," Journal of International Econonics 31, 203-229.

Garman, Mark B, and steven $\$$. Kohlhagen, 1983, "Foreign Currency option Values," Journal of International Money and Finance 2, 231-237.

Jorion, Philippe, 1988, "On Jump Processes in the Foreign Exchange and stock Markets," Review of Financial studies 1, 427-445.

Krugman, Paul R., 1991, "Target zones and Exchange Rate Dynamics," Quarterly Journal of Economics 106, 669-632.

Krugman, Paul, and Marcus Miller (eds.), 1992, Exchange Rate Targets and Currency Bands, Cambridge, UK: Cambridge University Press.

Lindberg, Hans, and Paul söderlind, 1991, Testing the basic target zone model on Swedish data. Seminar paper no. 485 , Institute for International Economic studies, University of stockholm.

Lindberg, Hans, and Paul söderlind, 1992, Target zone models and the intervention policy: The Swedish case. Seminar paper no. 496, Institute for International Economfc studies, University of stockholm.

Merton, Robert c., 1976, "option Priclng when Underlying stock Returns Are Discontinuous," Journal of Financial Economics 3, $125-144$.

Svensson, Lars E. 0., 1991, rTargets Zones and Interest Rate variability," Journal of International Economics 31, 27-54. 

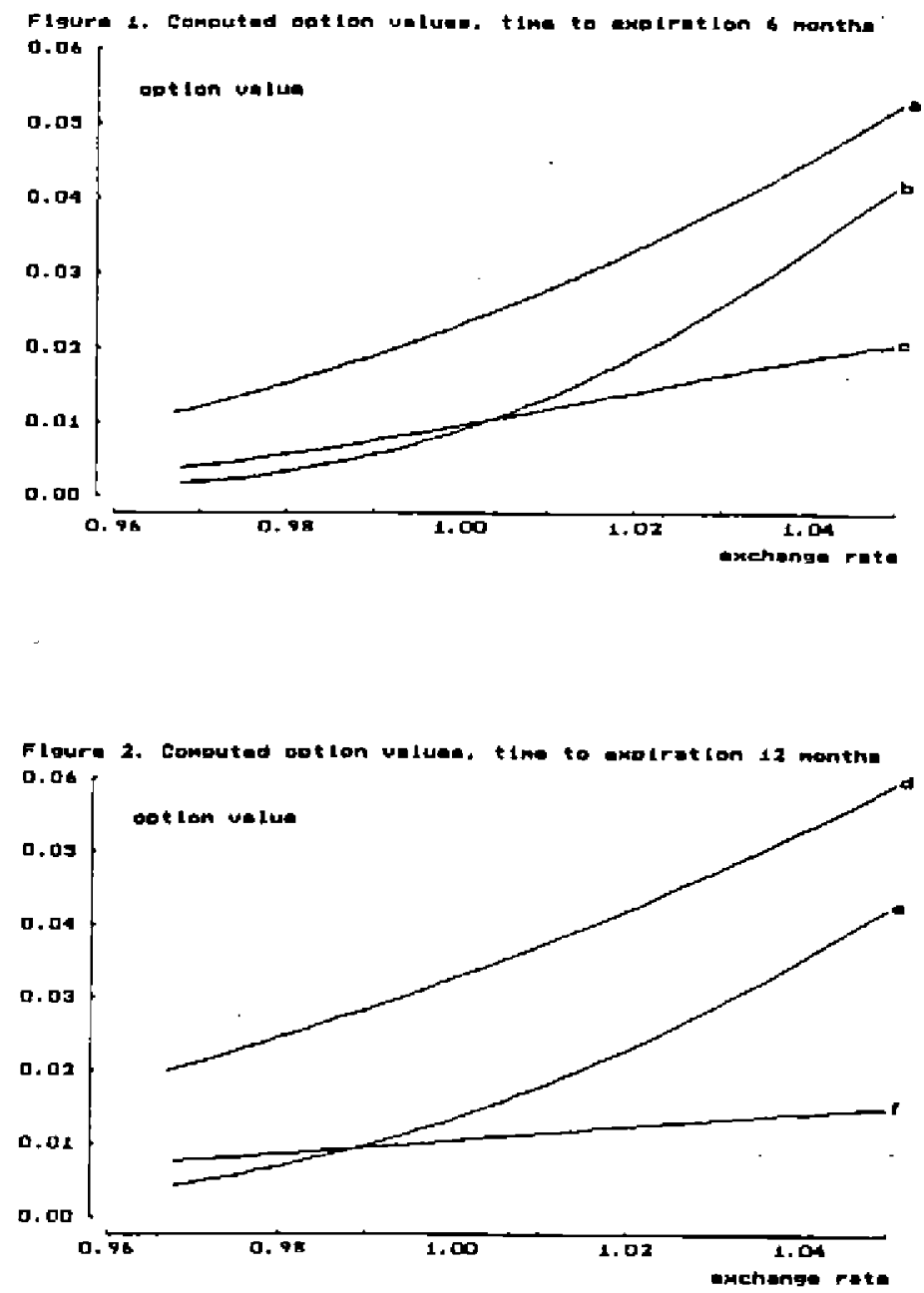